\title{
El "concierto sacro" del 19 de abril de 1810: o la conjura eclesiástica de Andrés Bello (1781-1865)
}

\author{
The "Sacred Contriving" of April 19th, 1810 or the \\ Ecclesiastical Conspiracy of Andrés Bello (1781-1865)
}

\author{
por \\ David Coifman Michailos \\ Fundación Camerata de Caracas \\ Academia Nacional de la Historia, Venezuela \\ dcoifman9@gmail.com
}

\begin{abstract}
El concierto sacro del Jueves Santo, 19 de abril de 1810, marcó el inicio del movimiento independentista de Venezuela. La fecha no fue escogida al azar, sino que a propósito de las ventajas que la "función eclesiástica" de ese día proporcionaba para el control social y la difusión de la información en torno a los hechos políticos que se buscaba alcanzar. El presente ensayo se propone examinar la confluencia musical y eclesiástica (hasta ahora no estudiada) que habría sin duda sido necesaria establecer para el positivo resultado de esta empresa, supeditada a las redes sociales, musicales e intelectuales en torno al editor entonces de la Gazeta de Caracas, hijo del músico y abogado Bartolomé Bello (1758-1804), el humanista Andrés Bello (1781-1865).
\end{abstract}

Palabras clave: Venezuela, Iglesia, 1810, Velásquez “el más joven”, Misa de requiem, Bartolomé Bello.

The sacred contriving on Maundy Thursday, April 19th, 1810, marked the beginning of the independence of Venezuela. The date was not chosen at random but on the basis of the advantages that the "ecclesiastical function" had regarding both the social control and the dissemination of the information about the political goals to be achieved. The purpose of this essay is the analysis of the hitherto unknown confluence of the musical and ecclesiastical elements that made it possible this enterprise to succeed. These elements in turn are related to the social, intellectual and musical networks of the humanist Andrés Bello (1781-1865), editor of the Gazeta de Caracas and son of the musician and lawyer Bartolomé Bello (1758-1804).

Key words: Venezuela, Church, 1810, Velásquez "the younger", Requiem Mass, Bartolomé Bello.

Las prescripciones de las Reglas de coro de la Iglesia Metropolitana de Caracas para el Jueves Santo, 19 de abril de 1810, se acataron de manera inexorable. A las seis de la tarde del día anterior, Miércoles Santo, se cantaron las tres Lamentaciones del profeta Jeremías con las que se iniciaba de manera oficial el Triduum Sacrum: tres días de luto por la crucifixión y muerte del hijo de Dios ${ }^{1}$. A las siete de la mañana

${ }^{1}$ Como en casi todas las provincias españolas ubicadas en la franja ecuatorial, el horario litúrgico era muy preciso con respecto al lapso nocturno y solar de 12 horas cada uno. De esta manera la noche litúrgica del Jueves Santo, por ejemplo, comenzaba a las seis de la tarde del Miércoles Santo y terminaba 
sonó la campana Santísimo Sacramento para llamar a la feligresía caraqueña a asistir al Oficio de Prima, a la Misa de las ocho y a la procesión por parte de la cofradía catedralicia del Santo Sepulcro. Con la doxología final de la plegaria eucarística se inició la prohibición de doblar las campanas hasta la entonación del Salve a las seis de la tarde del Sábado Santo. A las dos y media de la tarde, sonó el Chripitúsculo para llamar a la asistencia de la Seña, y a las tres al Mandato, hasta concluir las ceremonias en el rezo de las Completas. Se escuchó de nuevo el Chripitúsculo, durante media hora hasta las cinco de la tarde, cuando se celebró la Seña y los miembros de la Tribuna interpretaron las tres Lamentaciones de Viernes Santo. Con el toque de Queda por el Chripitúsculo, a las nueve de la noche, se llamó a la prohibición del libre tránsito por la ciudad, con penalidades que incluían prisión ${ }^{3}$. Fue un día de duelo catedralicio, verificado en el recibo de pago a los músicos extraordinarios que cantaron y tocaron la Misa matutina y las Lamentaciones vespertinas de aquel memorable Jueves Santo (véase lámina 1).

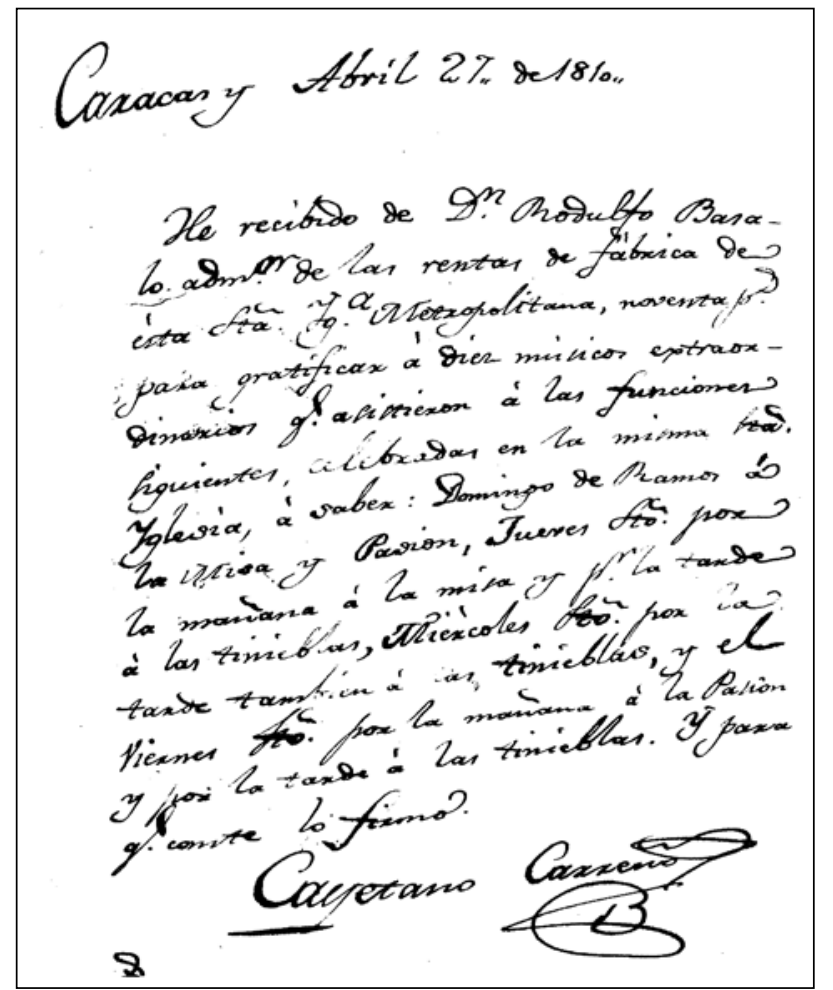

(Lámina 1) Recibo de pago por los músicos extraordinarios del Jueves Santo, 19 de abril de 1810

Se lee:

Caracas y Abril 27 de 1810 /

He recibido de don Rodulfo Basalo administrador de las rentas de fábrica de esta Santa Iglesia Metropolitana, noventa pesos para gratificar a diez músicos extraordinarios que asistieron a las funciones siguientes, celebradas en la misma Santa Iglesia, a saber: Domingo de Ramos a la Misa y Pasión, Jueves Santo por la mañana a la Misa y por la tarde a las tinieblas, Miércoles Santo por la tarde también a las tinieblas, y el Viernes Santo por la mañana a la Pasión y por la tarde a las tinieblas. Y para que conste lo firmo. / Cayetano Carreño (rúbrica)

Fuente: AGN, Iglesias LXII, fol. 116.

a las seis de la mañana, cuando se iniciaba entonces el día solar que concluía a las seis de la tarde. En cambio, la práctica horaria moderna incluye como "noche" la del mismo Jueves Santo desde las seis de la tarde hasta la medianoche.

${ }^{2}$ También conocida como matraca, es una rueda de tablas fijas con forma de aspa o cruz que suena de manera desapacible al dar vueltas sobre sí misma.

${ }^{3}$ Reglas de coro de la esta Santa Yglesia / Formadas en el año pasado de 1728 / Por el Ylt. S.r D. ${ }^{n}$ Juan de Escalona / De feliz recordación. / Publicadas el año de 1747 / Con algunos acordados hechos / por la R. ${ }^{l}$ Audiencia de S. ${ }^{\text {to }}$ / Domingo por coms. ${ }^{n}$ del R[ey] N[uestro] S[eñor], Archivo Arquidiocesano de Caracas (AAC), Libros Diversos 111-L, fols. 48-55. Documento inédito. 
No era pues un día de festejos sociales ni personales. Por el contrario, era la razón anual por la cual las mujeres criollas de la capa social más alta asistían a misa todas las mañanas del año con atuendos y mantillas de riguroso color negro como penitencia por la crucifixión y muerte del hijo de $\operatorname{Dios}^{4}$. Con todo, un acontecimiento insólito, y por lo mismo sin precedentes en la historia de la Iglesia católica en Venezuela, se verificaría aquel Jueves Santo, 19 de abril de 1810. Insólito no tanto por la rebelión religiosa que respaldó sino principalmente porque evidencia, como expresión del pináculo o conclusión exitosa de un premeditado proceso ilustrado de la Emancipación, la conjura eclesiástica de los mantuanos ${ }^{5}$. Se trata de la ausencia de las principales dignidades eclesiásticas en la sillería del coro -principalmente el canónigo José Cortés de Madariaga y el presbítero Francisco José Ribas, figuras de primer orden en los acontecimientos políticos verificados ese día- para cantar en canto llano el íncipit de la antífona Requiem eternam que introduce toda la ceremonia catedralicia del Jueves Santo, y más específicamente como puente sonoro hacia el salmo Te decet hymnus en la obra encargada expresamente para esta ocasión al músico del sector de los pardos José Francisco Velásquez "el joven" (1781-1822) ${ }^{6}$.

Para evitar la notoria ausencia de las dignidades catedralicias en la misa y procesión, Velásquez “el joven” sustituyó con las voces de la Tribuna el canto llano que debían entonar los ministros del coro (véase lámina 2). Manipulación musical que habría constituido un escándalo religioso y social de incalculables magnitudes dentro del seno de la Iglesia de no tratarse, sin embargo, de una calculada actuación eclesiástica en torno a los eventos que se gestionaron para hacer coincidir el "concierto sacro" (en términos musicales y sociales catedralicios) de ese Jueves Santo con los acontecimientos políticos que marcaron la transformación de la provincia española de Venezuela en república.

De hecho, ningún detalle de las acciones patrióticas desarrolladas ese día se consumó completamente al azar ${ }^{7}$. Los panfletos y proclamas, que anunciaban cual artificios de oráculo el éxito de la empresa, habían sido impresos el día anterior ${ }^{8}$. Bastaba con esperar a que se terminaran de celebrar las Completas, a las cuatro de la tarde, para que la Junta Suprema de Caracas anunciara en la Plaza Mayor (hoy Plaza Bolívar), ante el público asistente al "concierto sacro", la autonomía política y económica de Venezuela y la expulsión de sus cargos oficiales a los políticos "vecinos españoles residentes de la ciudad". Acontecimiento acordado, como se

${ }^{4}$ La vestimenta incluía una "manta" negra para cubrir la cabeza utilizada por las mujeres de la capa más alta de la sociedad venezolana, raíz etimológica del término "mantuanos" con el que se designó a todo el colectivo de la nobleza criolla. Véase Duarte 2001, I: 167-169.

${ }^{5}$ Sobre esta conjura criolla véase Quintero 2008 y Leal Curiel 2009.

"Sobre la vida y obra de Velásquez "el joven" véase Calzavara 1987: 329-331 y Coifman 2012. Este músico sustituyó a Carreño como director de la capilla catedralicia en la Fiesta de la Naval de Caracas, entre los años 1816-1821. Archivo Arquidiocesano de Caracas (AAC), Libro tercero de cuentas de la Archicofradía del Rosario, libros diversos 201-L, fols. 229 (año 1816), 235 (1817), 237 (1818), 242v (1819), 246v (1820) y 250 (1821).

${ }^{7}$ Véase, por ejemplo, Molina Martínez 2002.

8Véase Archivo General de Indias (=AGI), Audiencia de Caracas (=Caracas), leg. 969. 
recoge en el acta del cabildo secular de ese día, 19 de abril de 1810, "con motivo de la función eclesiástica del día de hoy, Jueves Santo”9.

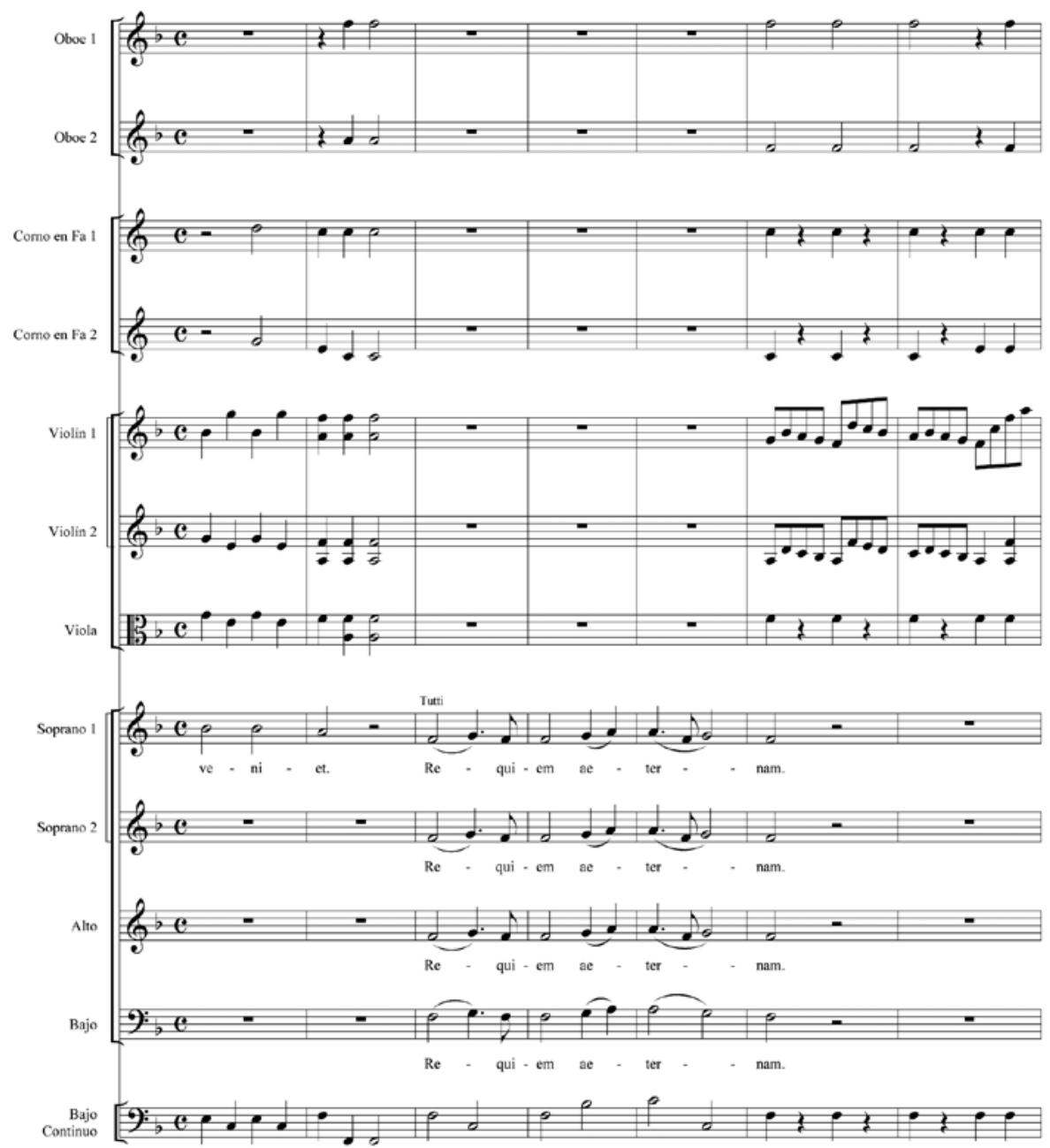

(Lámina 2) Monodia vocal a cappella (cc. 46-49) de la Tribuna para entonar el Requiem eternam de la Misa de difuntos, del 19 de abril de 1810 (cc. 44-50) ${ }^{10}$.

${ }^{9}$ Miranda Bastidas y otros 1999

${ }^{10}$ Transcripción musical de mi autoría. El original de 1810 puede consultarse en el Archivo Audiovisual de la Biblioteca Nacional de Venezuela, Foro Libertador, bajo el registro JAL 21-A. Un detalle importante es la manera como el autor se identificó en la obra, también sin precedentes entre los músicos del sector de los pardos: "compuesta por el Ciudadano José Francisco Velásquez". Fue reestrenada en concierto público por la Camerata Barroca de Caracas, dirigida por Isabel Palacios, en la Iglesia de San Francisco de Caracas, el 16 de abril de 2010, a propósito de los festejos venezolanos del 
Con todo, los integrantes y defensores de la Junta Suprema de Caracas debían todavía realizar el juramento religioso por la defensa venezolana del Rey, como finalmente lo hicieron con Misa y Te Deum solemnes, el domingo 29 de abril, siguiendo las pautas ceremoniales que la Junta de Gobierno sevillana, defensora de los derechos del rey Fernando VII, había establecido para este mismo propósito en la Capilla Real del Palacio de Aranjuez, el 25 de septiembre de 1808. Una idéntica ceremonia catedralicia fue solicitada por la Junta Suprema de Caracas al Cabildo eclesiástico, el lunes 23 de abril, la que supuso la realización de una sesión extraordinaria para acordar sobre esta urgente petición de los nuevos gobernantes.

En la ciudad de Caracas a 25 de abril de 1810; se juntó en su sala capitular a cabildo extraordinario el muy Venerable Señor Deán y Cabildo de esta Santa Iglesia Metropolitana a saber los señores doctor don Pedro Martínez deán, doctor don José Francisco López Méndez chantre, doctor don Juan Vicente de Echeverría magistral, doctor don Raymundo de Bolea racionero, doctor don Nicolás Antonio Osío, doctor don Domingo Díaz Argote y bachiller don Juan Agustín Díaz Argote medio racioneros, a que por justo impedimento no asistieron los demás señores capitulares, ni tampoco el señor gobernador de este arzobispado por el ilustrísimo señor arzobispo electo ausente, aunque todos fueron avisados por cédula ante diem para tratar acerca de un oficio de los señores alcaldes de 23 del corriente en que se sirven participar a este Cabildo, que consecuente con lo acordado por la Junta Suprema en el mismo día, debe celebrarse una función solemne en esta Santa Iglesia Metropolitana el 29 de este propio mes (en que cae la Dominica in Albis) con Te Deum en acción de gracias al Santísimo Sacramento por la feliz instalación del mismo Supremo Tribunal realizada en el 19 de este mismo mes corriente, a fin de que se disponga lo conveniente a su ejecución. Conferenciando el asunto los sobredichos señores unánimemente dijeron: que se ejecute lo que ha dispuesto la Suprema Junta con la pompa y gravedad que se acostumbra en esta Santa Iglesia Metropolitana y corresponde al importante y útil fin que lo motiva y a la congratulación de este Cabildo; y que con testimonio de esta acta y el oficio de estilo se participe a la misma Suprema Junta por medio de los sobredichos señores alcaldes. / Y continuándose el mismo tratado hecho al efecto la debida conferencia, unánimemente se acordó que para la sobredicha función, en el día precedente se repique solemnemente a las Avemarías del mediodía, y de la noche y en esta la correspondiente iluminación. Que el dicho día 29 se ejecute temprano los oficios y de misas y horas del día a la hora acostumbrada, se cante expuesto el Santísimo Sacramento Misa Solemne votiva pro re gravi $^{[11]}$ del mismo augusto misterio con la oración pro gratiarum actione en acción de gracias de la feliz instalación de la misma Suprema Junta, concluyéndose con solemne Te Deum en la forma acostumbrada para tales funciones que con la Suprema Junta se practiquen en su entrada, estación y despedida de esta iglesia, todas las ceremonias que se han practicado con la Real Audiencia; y que el costo de la iluminación se saque de las rentas de fábrica contribuyéndose por su mayordomo don Rodulfo Basalo bajo la

Bicentenario de la Independencia. Una grabación de esta obra puede ser consultada en Monumenta: La música colonial venezolana, vol. V. Cf. discografía recomendada.

${ }^{11}$ Se traduce "por causa grave" o importante. 
intervención y visto bueno de los señores diputados para libranza de gastos ordinarios en el presente año. Con lo que se concluyó y firmaron de que certifico.= (rúbricas) ${ }^{12}$.

La invitación a la ceremonia catedralicia fue publicada en el trascoro de la catedral, el 26 de abril, por el Provisor y Gobernador del Arzobispado doctor don Santiago Zuloaga, y un mes después en la Gazeta de Caracas ( $\left.\mathrm{N}^{\mathrm{o}} 100\right)$, del 25 de mayo de 1810, para dejar saldadas de manera pública las justificaciones que dieron lugar a la instalación de la Junta Suprema de Caracas, en orden de prioridades, "por la Religión, por el Rey y por la Patria".

Circular del Gobernador de este

Arzobispado á los Curas, Vicarios y

Misioneros de su distrito.

Por la feliz instalación de la Suprema Junta de esta capital, que haciendo cesar las antiguas autoridades ha reasumido en sí el poder soberano impedido hasta ahora por la injusta prisión que sufre en Francia nuestro muy amado Rey D. Fernando Séptimo cuya vida conserve el Altísimo por muchos años; dispondrá V. con acuerdo del Juez Real que en esa Parroquial, y en todas las demás de ese partido acordados sus curas con los respectivos jueces territoriales se cante un solemne Te Deum con precedente Misa votiva pro re gravi del Santísimo Sacramento, y la oración pro gratiarum actione, y Sermón si fuese posible, expuesto el Santísimo Sacramento, en acción de gracias de aquella instalación. Y continuarán las rogativas prevenidas, dirigiéndolas también á implorar la divina luz por el mejor acierto de este Supremo Tribunal en sus providencias por la Religión, por el Rey y por la Patria. Y de la execusión me dará puntual aviso.

Dios guarde á V. muchos años. Caracas 26 de Abril de 1810.=Dr. Santiago de Zuloaga13 .

Finalmente, el $1^{\circ}$ de mayo ${ }^{14}$, los músicos extraordinarios recibieron del administrador de fábrica de la catedral, Rodulfo Basalo, la cifra total de 20 pesos por haber interpretado junto con la capilla catedralicia la Missa Solemnis ${ }^{15}$ compuesta especialmente para este acontecimiento por el bajonista de la catedral y compositor criollo José Ángel Lamas (1775-1814)16. Los honores catedralicios (y musicales) a la Junta Suprema eran pues así comparables con los que, hasta entonces, sólo habían sido ofrecidos a la Real Audiencia de Caracas.

¿Quienes, sin embargo, con tanta premeditación y profundo conocimiento de los mandatos de las Reglas de coro, eventos litúrgicos y detalles musicales, habrían podido sostener el equilibrio de la razón en el seno mismo de la máxima institución

${ }^{12}$ Archivo de la Catedral de Caracas (ACC), Actas del Cabildo Eclesiástico (=ACE), libro XXIV, fols. 102v-103.

${ }^{13}$ Gazeta de Caracas, № 100 (25 de mayo de 1810).

${ }^{14}$ Archivo General de la Nación (=AGN), Iglesia, tomo LVII, fol. 129.

${ }^{15}$ Se trata, de hecho, de la única misa escrita por el compositor venezolano, siendo por tradición denominada "Misa en Re" sin mayor lógica al no necesitar distinguirse por la tonalidad. Véase, por ejemplo José Ángel Lamas: Misa en Re. Partitura de coro y orquesta, en Lira Espejo 1959. Al ser pues la única misa solemne de este compositor, la he denominado "Missa Solemnis". Véase Coifman 2011: 38.

${ }^{16}$ Sobre la vida de José Ángel Lamas en general véase Calcaño 1958/1980: 141-151; Plaza 1990:149; Guido 1982: 5-9; Calzavara 1987: 276-278 y Coifman 2011 b. 
católica en Venezuela para justificar la realización de estas dos trascendentes ceremonias catedralicias caraqueñas (y sus exclusivas obras musicales), para evitar el caos catedralicio y el escándalo público que le sobrevendría de haber fracasado la "rebelión eclesiástica" del 19 de abril de 1810? La respuesta, como veremos, se sostiene en un concierto de "coincidencias" dirigidas de manera magistral (y en mi opinión de forma maquiavélica sin duda) por el editor de la Gazeta de Caracas, el humanista Andrés Bello (1781-1865), primogénito del músico de la catedral caraqueña y profesor de canto llano del Seminario Santa Rosa de Lima de la Real y Pontificia Universidad de Caracas, Bartolomé Bello (1758-1804). Reconstruir el tramado armónico de las "voces", temas y motivos "organizados" alrededor del concierto sacro caraqueño del Jueves Santo, 19 de abril de 1810, es pues el principal objetivo del presente ensayo.

\section{DE CÓMO BARTOLOMÉ BELLO PREFIRIÓ HACER PASAR HAMBRE A SU FAMILIA POR DEFENDER LA REBELIÓN CATEDRALICIA DEL MES DE ABRIL DE 1787}

La carrera profesional del cantante Bartolomé Bello, centrada en la vida clerical y en la música eclesiástica de la Iglesia Catedral de Caracas, fue cercenada por dos trascedentes acontecimientos ${ }^{17}$. El primero, el nacimiento de su primogénito Andrés Bello, el 29 de noviembre de 1781, luego de casarse dos meses antes (el 8 de septiembre) con Ana Antonia López, hija del afamado pintor, dorador y escultor venezolano Juan Pedro López (1724-1787), sin duda para atajar el escándalo social que seguramente despuntaba junto con los avanzados siete meses de gestación de la madre. Y el segundo, la rebelión catedralicia en la que estuvo envuelto durante la realización de la primera Seña de Cuaresma, de 1787, que lo llevó a renunciar de manera irrevocable a su cargo. Dos eventos de enormes repercusiones éticas, morales y religiosas en la época, que Andrés Bello acalló con el silencio que le impuso a su juventud, y al pasado familiar en general, sobre su vida caraqueña (1781-1810). Pero fueron sin duda las razones del escándalo público que vivió su padre las que lo afectarían de por vida, principalmente por la precaria situación económica a la que estuvo sometido por injustas causas. Sacrificio paterno que el humanista debió recordar en vísperas de la Semana Mayor de cada año, pero con mayor razón en el mes de abril de 1810.

Los orígenes de la rebelión de Bartolomé Bello se centran en los acontecimientos vividos la década previa a 1787. El músico se había iniciado como cantante de la Iglesia Catedral de Caracas durante su asistencia a las fiestas decembrinas de 1770 , poco tiempo después de haber llegado a la provincia uno de los obispos más déspotas de la historia de la Iglesia en Venezuela. La movilización de don

${ }^{17}$ Bartolomé Bello nació en Caracas, en la parroquia de San Pablo, el 21 de agosto de 1758. Solicitó vestir hábitos clericales el 4 de julio de 1773, contando casi 15 años de edad. Condición de religioso que parece haber mantenido hasta dos meses antes de nacer su primogénito, cuando contrajo matrimonio el 8 de septiembre de 1781. Véase Año 1773 / Ynformación de limpieza de sangre, buena vida y costumbre dada por D. ${ }^{n}$ Bartholomé Bello para vestir avitos clericales, AAC, Petición de hábitos 4-Ec. 
Mariano Martí a la diócesis de Caracas, que no estaba contemplada por la Cámara del rey Carlos III ${ }^{18}$, coincidió con el ruego del Consejo de Indias al monarca para despedirlo de su obispado de Puerto Rico debido a los escandalosos conflictos públicos que mantenía con su Cabildo eclesiástico. Tan sonados eran en la Corte española los problemas del obispo en la isla caribeña, que el rey Carlos III pensó que su traslado a la silla obispal vacante de Caracas, y "la mudanza de clima", bajarían los temperamentos acalorados del obispo ${ }^{19}$. Sacrosanto error. Los conflictos del obispo Martí con los capitulares caraqueños no se hicieron esperar. En menos de un año de haberse establecido en Caracas, el obispo Martí había repetido las causas que avivaron las querellas con su capítulo de Puerto Rico ${ }^{20}$. Y para evadirlas, Martí interpuso (como en Puerto Rico) la necesidad de realizar la visita pastoral a su nuevo obispado de Venezuela, cuya ausencia de la capital prolongó durante casi trece años, en contradicción con lo que había anunciado al Gobernador José Carlos de Agüero y al rey Carlos III de no dilatarla en más de cuatro o cinco años ${ }^{21}$.

La principal causa del conflicto con el Cabildo eclesiástico caraqueño halla sus orígenes en la compulsiva erogación económica que el obispo le exigió al capítulo eclesiástico para mejorar y aumentar la proyección pública del culto catedralicio. Y por lo mismo, aclamar a viva voz su nuevo poder obispal. Se llevó a cabo así un rápido incremento de los llamados "ministros subalternos" del coro, gracias a la nueva erogación económica que para este propósito se hizo desde la mesa capitular. Desde entonces, los músicos aprobados por el documento de Erección del Obispado, en 1532, y los aumentados que habían sido aprobados en 1698 junto con las Constituciones Sinodales de Venezuela (1687), pagados por la fábrica de la catedral, contaron no sólo con considerables aumentos salariales sino también con la ayuda estable de músicos supernumerarios denominados "foráneos" (= externos a los documentos citados) pagados de la novena capitular. Aumentos del sueldo y del personal "para mayor culto" que requerían la convocatoria obispal de un Regio Placet (concilio provincial) para proceder a legitimarlos junto con las reformas que el Cabildo eclesiástico exigía también a las retrógradas Sinodales del siglo XVII. Peticiones capitulares que el obispo Martí se negó a realizar de manera

${ }^{18}$ Véase Año 1770 / Cámara / Relación de Personas para Consultar el Obispado de la Iglesia Catedral de Santiago de León de Caracas, AGI, Caracas 218 (16 folios).

${ }^{19}$ Informe (Madrid, 11 de agosto de 1772), AGI, Caracas 230, fols. 1-6.

${ }^{20}$ Entre los principales conflictos se incluye los derivados del arreglo del órgano grande de la catedral a cargo del organero español José Mathías Fonte del Castillo. Al respecto, véase Coifman 2006. Trabajo revisado para mi libro De obispos, reyes, santos y señas en la historia de la capilla musical de Venezuela (1532-1804) (Coifman 2010).

21 "Señor / En cumplimiento de mi obligación doy cuenta á Vuestra Majestad que vuestro reverendo obispo ha salido a emprender su visita pastoral, y según lo dilatado de su diócesis ocupará el tiempo de cuatro o cinco años en finalizarla; y en consideración de tan dilatado tiempo, ha nombrado por provisor al doctor don Miguel Muñoz que lo fue en el del difunto obispo Abadiano, sujeto de literatura aunque teólogo y de particular conducta [...]”. Carta (Caracas, 4 de diciembre de 1772), AGI, Caracas 320 (1 folio). 
reiterada sobre la también reiterada excusa de hallarse "muy ocupado" en la visita pastoral del obispado ${ }^{22}$.

En represalia, el Cabildo eclesiástico decidió, en sesión capitular del 11 de noviembre de 1783, no sólo dejar de pagar de su novena capitular los aumentos salariales de los ministros "de erección" y "de aumento" pagados por el obispo, sino también aumentar según "la habilidad y circunstancia" del solicitante, los sueldos a los ministros y músicos "foráneos" contratados por su mesa capitular23. Como resultado, los integrantes del coro que estaban siendo pagados por cuentas de la fábrica de la catedral, entre ellos el cantante "de aumento" Bartolomé Bello, comenzaron a percibir sueldos muy por debajo de los que recibían los otros ministros y músicos subalternos pagados por la mesa capitular ${ }^{24}$. Y como no habría podido resultar de otra manera, los ministros de coro y músicos de la Tribuna afectados (incluidos los llamados "foráneos") decidieron presionar al obispo Martí. Para ello llevaron a cabo la primera huelga catedralicia significativa en la Caracas del siglo XVIII. Toda ocasión para pedir o adelantar el patitur y el recle estaba pues bien infundada, y el escándalo público no se hizo esperar. El acta capitular del 23 de febrero de 1787 recoge el alcance de la huelga catedralicia a la fecha:

[...] que hallándose penetrados todos y cada uno de sus individuos del suceso acaecido esta mañana de no haberse cantado en la hora prima el martirologio que por institución [de las Reglas de coro] debe cantarse en esta hora canónica por uno de esta naturaleza nunca vista hasta ahora en esta santa Iglesia, se les ha renovado con la mayor intención el dolor de que haya llegado a este extremo el culto divino de esta santa Iglesia que tantos años hace tiene abandonado muchos de los capellanes de su coro sin modo, ni arbitrio de atraerlos y sujetarlos el Cabildo al cumplimiento de su obligación y asistencia diaria a todas las horas canónicas, y funciones sagradas a que están adscritos los llamados de erección, y respectivamente por sus fundaciones los que se dicen foráneos ${ }^{25}$.

La celebración de la Cuaresma y la Semana Mayor en la máxima institución católica del obispado de Venezuela, aquel mes de abril de 1787, no contaba con el mínimo número de capellanes de coro disponibles para cantar en canto llano las ceremonias de la primera Seña. Por tal motivo, el deán José Lorenzo Borges (en representación del obispo) le exigió a Bartolomé Bello que bajara de la Tribuna

\footnotetext{
${ }^{22}$ En sesión capitular del 29 de julio de 1783, el Cabildo eclesiástico es explícito en cuanto a no demandar más del obispo Martí la aprobación de los aumentos solicitados, y hacer efectivas sus quejas al rey: "[...] acordó unánimemente que por no restar ya la menor esperanza de conseguirse remedio alguno de Su Señoría Ilustrísima, ni de su tribunal, se dé cuenta a Su Majestad, que Dios guarde, en su Real y Supremo Consejo de estas Indias con los documentos y certificados de cuadrantes y oficios mencionados, comprobantes de las solicitudes de este Cabildo en desempeño de su obligación y deseo del mejor servicio del culto divino de esta santa Iglesia”. En ACC, ACE XVIII (duplicado), fols. 42-42v. En cuanto a la Real Cédula, fechada en 1773, solicitando al obispo Martí la realización de la sínodo diocesana, y las posteriores negativas, pueden consultarse en AGI, Caracas 226.

${ }^{23} \mathrm{ACC}, A C E$ XVIII (duplicado), fol. $50 \mathrm{v}$.

${ }^{24}$ ACC, ACE XVIII, fols. 92-95.

${ }^{25}$ ACC, ACE XIX, fols. 337-337v.
} 
para satisfacer estas urgencias musicales. La excusa interpuesta por Bello para no acatar la orden del deán es memorable por ridícula: "llevo espada en la cinta"26. Y como Bello no quiso bajar, ninguno de sus amigos músicos en solidaridad quiso bajar, ratificando pues así que lo de la "espada en la cinta" era una falsa excusa. Finalmente, el hostigamiento de las multas impuestas a Bello por sus negativas a prestarse a esta sustitución para cantar las siguientes Señas lo hizo renunciar. Que Bello prefiriera renunciar a recapacitar, siendo a la fecha abogado por la Audiencia de Santo Domingo, evidencia que el músico creía firme y fielmente en la huelga. Bajar a sustituir a los ministros del coro ausentes significaba para Bello una traición al compromiso que movió a sus amigos músicos a apoyarlo.

Las consecuencias laborales de tal decisión le debieron resultar sin duda muy frustrantes. El único empleo que Bello consiguió disponible se lo ofreció el gobernador Juan Guillelmi, el 20 de abril de 1789, para ocupar el cargo de Fiscal de la Real Hacienda de la ciudad de Cumaná. Bartolomé Bello no comenzó a ejercer hasta el 7 de julio de ese mismo año, con el bajo sueldo de 200 pesos anuales -salario idéntico al que habría percibido en la Tribuna catedralicia desde 1770 de haber contado con la suficiente habilidad para cubrir la plaza de "organista primero" en las muchas ocasiones que ésta estuvo vacante antes de introducir su irrevocable renuncia, en 1787. Ciertamente este salario también estaba muy por debajo del que habría seguramente obtenido como maestro de capilla de haber permanecido en funciones como músico de la catedral hasta finales del siglo. Con todo, el 20 de enero de 1790, Bello ocupó al mismo tiempo el cargo de Fiscal de la Real Renta del Tabaco de dicha ciudad. Pero no fue hasta el 24 de marzo de 1793, cuando solicitó al Rey, en su Consejo de Indias, el aumento de sueldo que se creía acreedor por ejercer también los cargos de Asesor y Auditor de Guerra. El 17 de junio de 1797, el Consejo de Indias le respondió no tener lugar el aumento salarial, "pero sí que se tenga presente su mérito para atenderle con oportunidad" 27 , que nunca llegó antes de verificarse su muerte en Cumaná, el 25 de julio de 1804.

\footnotetext{
${ }^{26}$ La expresión no es original de Bartolomé Bello, sino del presbítero Agustín Flores, testigo y amigo del músico que lo defendió de los acontecimientos ante el tribunal eclesiástico durante el interrogatorio de esta manera: "Que el expresado licenciado Bello renunció la plaza de música porque en la primer seña de Cuaresma presente mandó el señor deán bajasen los músicos de la Tribuna al coro bajo a cantarla, y como el dicho licenciado no viste hábitos clericales, sino ciñe espada a la cinta, no bajó, y porque el dicho licenciado no bajó, tampoco quisieron bajar los demás músicos, y el señor deán los multó a todos en la falla y en dos [pesos] por cada una, y a la segunda seña porque tampoco concurrió el licenciado Bello le multaron en cuatro pesos y la falla, lo que le estimuló a renunciar la plaza que ejercía”. En Testimonio / Numero 4 / Contiene la justificación evacuada acerca de los ministros subalternos que se han apartado del servicio del Coro y Capilla de Musica de la Cathedral de Caracas, y plazas que están vacantes, y de los motivos porque aquellos se retiran, y estas no se han provehido, AGI, Caracas 964 (23 folios), fol. 3v. Esta defensa de Flores habría estado pactada con el músico por lo ridícula de la excusa, que los demás músicos tomaron como suya para no bajar, ridiculizando así la verdad: que ninguno de los músicos de la Tribuna, ni el sueldo así lo incluía, estaba obligado a sustituir a los capellanes de coro, que para más señas del día estaban ejerciendo presión hacia el obispo por su negativa a aumentarles los sueldos.

${ }^{27}$ En vista de la instancia de don Bartolomé Bello, fiscal de la Real Hacienda y Renta del tabaco de la Provincia de Cumaná, que sirve también la plaza de Asesor y Auditor de Guerra de aquel gobierno, AGI, Caracas 816 (29 folios).
} 
La rebelión catedralicia de Bartolomé Bello contra el despotismo del obispo Martí le reportó morir alejado de su primogénito. Para el joven Andrés Bello significó padecer las limitadas posibilidades económicas de su niñez. La conjura eclesiástica de los mantuanos, del 19 de abril de 1810, reivindicaría sin duda las decisiones del músico, como veremos.

\section{DE CÓMO BARTOLOMÉ BELLO DEFENDIÓ A SANGRE Y FUEGO AL AMIGO MÚSICO JOSÉ FRANCISCO VELÁSQUEZ "EL VIEJO”, PADRE DEL COMPOSITOR DE LA MISA DEL 19 DE ABRIL DE 1810}

El 13 de septiembre de 1790, el cantante del sector de los pardos Juan Julián Arias Mota inició un juicio escrito contra el músico pardo José Francisco Velásquez "el viejo” (1755-1805), padre del citado músico José Francisco Velásquez "el joven”, por el cobro de 57 pesos, 2 reales $^{28}$. Las causas del litigio se remontan a las celebraciones realizadas con ocasión a la jura y proclamación caraqueñas del rey Carlos IV, entre el 12 de diciembre de 1789 y el 6 de enero de 1790. Como Velásquez ni Arias habían sido considerados para participar en los muchos festejos que las cofradías de pardos de la ciudad realizaron en las fechas, decidieron incorporarse a las actividades musicales que se llevarían a cabo por la misma ocasión en las ciudades venezolanas de Calabozo y Valencia.

Para el viaje compraron fiado en las tiendas del militar pardo Nicolás Churión y de don Miguel Méndez. Las ganancias económicas fueron sin embargo tan exiguas, que a su regreso a la capital el cantante Arias demandó por la vía verbal a Velásquez por la deuda que tenían con Churión para evitar, en parte, que su "amigo" se le adelantara dada su "conocida malicia". Para contrademandar a Arias por la vía escrita, Velásquez pidió prestados 30 pesos a su cuñado Juan Manuel Olivares (1760-1797), organista del Oratorio San Felipe Neri de Caracas. Sin embargo, Arias se le había de nuevo adelantado porque el juicio verbal sólo le garantizaba el cobro de 20 pesos del total de 77 pesos, 2 reales que le adeudaban al comerciante y éste amenazaba con encarcelarlos. Se entabló así la disputa legal entre los "amigos" músicos mientras otra de índole moral dejaba constancias escritas sobre los posibles orígenes de la famosa leyenda decimonónica conocida hoy día como "Escuela de Chacao"29.

El 25 de septiembre de 1790, Arias explicó al juez que era propia de la malicia de Velásquez el intento de entretener la causa del juicio con la petición de sumarle a la deuda los 30 pesos que pidió prestados a su cuñado Olivares. Petición de Velásquez que el juez rechazó por considerarla ciertamente absurda. Arias también le pidió al juez que le exigiera a Velásquez pagarle en menos de veinticuatro horas los 20 pesos que había ganado con el juicio verbal para permitirle intervenir como

${ }^{28}$ Juicio contra José Francisco Velásquez, Archivo Histórico de la Academia Nacional de la Historia, Civiles 9-3710-1, año 1791 (32 folios). Véase también David Coifman, "José Francisco Velásquez 'el viejo’ (1755-1805): músico de cofradías y milicias de la Venezuela colonial” en Coifman 2010:597-599.

${ }^{29}$ Véase Walter Guido y León Zapata, “Chacao, Escuela de”, en Guido y Peñín 1998, I, 366-369. En cuanto a mi opinión sobre los orígenes de esta leyenda véase mi estudio "La música en el Oratorio San Felipe Neri de Caracas (1763-1777)”, en Coifman 2010: 239-305. 
demandante en el proceso escrito ${ }^{30}$. El juez consideró justa la solicitud de Arias y el 16 de noviembre dio al compositor un plazo máximo de tres días para saldar la deuda o ser encarcelado. Ese mismo día, el abogado de Velásquez explicó al tribunal que siendo su defendido "Subteniente del Batallón de Pardos de los Valles de Aragua" quería acogerse al derecho de que el juicio se remitiera a los tribunales castrenses, bajo sumario y secreto militar, lo que el juez también desestimó.

El 20 de noviembre, Velásquez pidió al juez que de su salario mensual de 15 pesos se descontaran 5 para pagar en cuotas la deuda, porque necesitaba el saldo para mantener a su "mujer e hijos". El $1^{\circ}$ de diciembre, el abogado de Arias endureció sus argumentos al exponer que el sueldo de Velásquez, "por estar instruyendo a los que se ejercitan en la música de la Tropa de Milicias", podía "acabarse en este mes o en el siguiente", lo que daría lugar a que los fiadores arremetieran contra su defendido. Además, Arias denunció que la oferta de Velásquez demoraba el pago de la deuda, junto con ser otra estrategia propia de la "conocida malicia" del compositor para jamás pagarla. Pasado el plazo establecido de tres días, Arias exigió al juez hacer efectiva la promesa de llevar preso al compositor. El 2 de diciembre, el alguacil mayor se presentó en la casa del músico para exigirle el inmediato pago de la deuda, quien contestó no poder saldarla. El 3 de diciembre, Velásquez es arrestado en los cuarteles militares de Caracas.

El 4 de enero de 1791, Velásquez envió al juez desde la cárcel un conmovedor escrito para jurar en nombre de Dios, teniendo como testigo y confidente al presbítero y músico Pedro Palacios y Sojo (1739-99) ${ }^{31}$, que pagaría la deuda en cuotas contando como fiador a su cuñado Juan Manuel Olivares. La amistad del nerista Palacios y Sojo con los principales músicos de Caracas, pero en particular con Bartolomé Bello, tiene sus orígenes conocidos en la visita que realizó este último al presbítero en el pueblo de Chacao, en enero de 1783, para pedirle su opinión acerca de dos Lamentaciones de Viernes Santo, un gradual y un ofertorio de Jueves Santo, compuestos por el músico pardo José Antonio Caro de Boesi (17581814?). La catedral quería comprar estas obras, como efectivamente lo hizo con la aprobación de Palacios y Sojo, el 14 abril de $1783^{32}$. De todos los asistentes al Triduum Sacrum de la Semana Mayor de 1810, Andrés Bello habría sido sin duda el único en recordar la estrecha deuda que la catedral tenía con su difunto padre por la consecución de la música que se cantaba anualmente en la catedral de Caracas en Jueves Santo.

Gracias a la credibilidad que la petición de Velásquez ganaba con la intermediación del presbítero Palacios y Sojo, el cantante Arias accedió a la propuesta

${ }^{30}$ Juicio contra José Francisco Velásquez, fol. 7 (cf. nota 28).

${ }^{31}$ Un incontable número de referencias inéditas extraídas del Archivo General de Indias, en Sevilla, y otros archivos históricos venezolanos sobre Pedro Palacios y Sojo y su Oratorio San Felipe Neri, que he distribuido en tres capítulos de mi libro De obispos, reyes, santos y señas...(Coifman 2010), permiten formarnos una parcial idea de la biografía (aún inédita) de este emblemático músico colonial venezolano.

${ }^{32}$ Coifman 2007:415-433. Trabajo ampliado bajo el título "José Antonio Caro 'de Boesi' (1758¿1814?): músico 'oficial' del Oratorio”, De obispos, reyes, santos y señas... Coifman 2010: 430-55. Una selección musical de su obra, en edición de mi autoría, se ha incluido en el primer volumen de la colección Monumenta: La música colonial venezolana. Véase "discografía recomendada” en la bibliografía. 
con la condición de involucrar en la aceptación al comerciante Churión para evitar la cárcel en caso de que el músico, dada su "conocida malicia”, mintiera. La siguiente y última carta, fechada el 16 de febrero, descalificaba magistralmente los temores de Arias al recriminarle no haber poder terrenal para dudar de la palabra del compositor. Esta no sólo estaba respaldada por la piadosa referencia social del citado presbítero, sino también por la situación económica de Juan Manuel Olivares: "sujeto de conocido abono y arraigo para el aseguramiento de las contribuciones de cinco pesos mensuales". El elocuente abogado y último mediador de los intereses de los músicos Velásquez, Palacios y Olivares, era el cantante Bartolomé Bello. El 19 de febrero, intimidado sin duda tanto por el gremio de músicos al que pertenecía como por la argumentación legal de Bello, Arias aceptó que Velásquez le pagara la deuda en cuotas teniendo por fiador a Olivares y tomando la palabra del músico Palacios y Sojo. Velásquez consiguió así la libertad, el 15 de abril de 1791.

El acontecimiento no habría sin duda pasado desapercibido para el joven Andrés Bello al ser la segunda ocasión (conocida) en que su padre dejaba a un lado las obligaciones laborales en Cumaná -quizá con igual riesgo de perderlaspara ejercer la defensa de sus amigos músicos en Caracas ${ }^{33}$.

3. DE CÓMO ANDRÉS BELLO Y JOSÉ FRANCISCO VELÁSQUEZ "EL JOVEN", CON LA LECCIÓN BIEN APRENDIDA DE 1808, UNIERON SUS INGENIOS EN LA CONJURA ECLESIÁSTICA DEL JUEVES SANTO, 19 DE ABRIL DE 1810

El historiador venezolano Manuel Pérez Vila, en el "Estudio preliminar" para la edición del segundo de los diez tomos que integran la publicación facsimilar de la Gazeta de Caracas por la Academia Nacional de la Historia de Venezuela (1983), resume con precisa elocuencia los acontecimientos eclesiásticos y políticos caraqueños que se conmemoran el 19 de abril de 1810.

El Jueves Santo, día 19 de abril de 1810, se produjo la crisis que [el Capitán General] Emparan temía. Tuvo su epicentro en el Cabildo Municipal de Caracas, foco del poder de los mantuanos, quienes ahora -bien aprendida la lección de 1808- se habían asegurado el concurso de muchos jefes militares de los batallones veteranos y de milicias, así como el apoyo de sacerdotes, intelectuales, artesanos, y un sector del pueblo llano. Creyendo, o aparentando creer, que los franceses dominaban enteramente a España, los revolucionarios presionaron al Gobernador Capitán General Emparan para que aceptase la formación de una Junta similar a las que en 1808 se habían constituido en la Metrópoli. Son bien conocidos los sucesos que condujeron al alto funcionario español a renunciar. Aquellas palabras suyas -“¡Pues yo tampoco quiero mando!,” dichas desde

${ }^{33}$ Cabe hacer notar, al menos de manera anecdótica, que José Francisco Velásquez "el joven" nació el 23 de marzo de 1781, cuatro meses después de la boda de sus padres, el 14 de noviembre de 1780. Fue bautizado por Pedro Palacios y Sojo. Si había algo que habría identificado a Bello con Velásquez, además de la condición de músicos, fue sin duda la razón que los obligó a ambos a contraer matrimonio bajo idénticas circunstancias. 
el balcón del cabildo [secular], ante la repulsa del pueblo, o de un grupo de conjurados congregados en la Plaza Mayor, señalan el principio del fin del régimen español en Venezuela. De inmediato fue constituida la que oficialmente llevó el nombre de "Suprema Junta Conservadora de los Derechos de Fernando VII en Venezuela", pero se designó a sí misma, ya desde el comienzo, como "Nuevo Gobierno". Y en efecto, lo era. Estaba integrada por 23 miembros presididos por los que hasta ese día eran los dos Alcaldes del Cabildo, Martín Tovar Ponte y José de Las Llamozas, pero creó una nueva estructura administrativa con cuatro Secretarías, que eran los instrumentos de su soberanía: la de Estado, o Relaciones Exteriores (Juan Germán Roscio), la de Guerra y Marina (Lino de Clemente), la de Hacienda (Fernando Key Muñoz), y la de Gracia y Justicia (Nicolás Anzola). Como ocurre generalmente en los cuerpos colegiados, no había en su seno unanimidad de opiniones, pero existía un grupo de revolucionarios convencidos (Roscio, Ustáriz, Tovar, Cortés Madariaga, José Félix Ribas, entre otros) que estaban decididos a llegar hasta el objetivo final: La Independencia de Venezuela. Estaba en marcha el proceso que condujo del 19 de abril de 1810 al 5 de julio de $1811^{34}$.

Pérez Vila prosigue explicando el importante papel que jugaron los artículos de corte revolucionario publicados por Andrés Bello en la Gazeta de Caracas para preparar las ideologías de quienes apoyaron los acontecimientos citados. Temas como "La ilustración y la virtud hacen a las naciones libres e independientes" ( $\mathrm{N}^{\circ} 86$, del 25 de febrero de 1810) y "La libertad de la prensa es la base principal de la ilustración pública" ( $\mathrm{N}^{\circ} 89$, del 16 de marzo y $\mathrm{N}^{\circ}$ 92, del 6 de abril), son dos de los axiomas independentistas utilizados con premeditación para los efectos deseados por Bello. La Gazeta de Caracas no tenía sin embargo una difusión "de masas", como la que hoy se recoge de los eclécticos periódicos informativos modernos, en virtud de los dos grupos sociales mayoritarios que la podían pagar: los mantuanos civiles, quienes por definición eran el sector terrateniente con mayor ingreso económico de la provincia, sin cuya ilustre participación habrían sido impensables los sucesos del 19 de abril y el clero, cuya postura conservadora habría representado sin duda la mayor resistencia a los cambios políticos deseados.

Por esta razón, Bello incluyó algunos artículos de actualidad religiosa, entre los que destacarían por su tono dramático el intitulado "Letras Apostólicas" del Papa Pío VII. Este Breve Pontificio resumía la ira de los feligreses católicos con ocasión a las sangrientas y expugnables actuaciones napoleónicas contra el Vaticano, si bien en sus párrafos finales se recogía el perdón cristiano para todos los pecadores que concebían el mal enceguecidos por el poder. Como norma editorial de Bello para todos los artículos de gran extensión publicados en la Gazeta, el Breve Pontificio debió dividirse en tres entregas ( $\mathrm{N}^{\circ} 81$, del 26 de enero; $\mathrm{N}^{\circ} 82$, del 2 de febrero y $\mathrm{N}^{\circ} 85$, del 16 de febrero de 1810). Quedó así estratégicamente postergado entre los civiles en general, y el clero en particular, el conocimiento de este perdón papal para quienes habían proferido enorme daño a la Iglesia católica.

Ningún artículo previo a los acontecimientos del 19 de abril publicado en la Gazeta de Caracas obtenía de esta manera mayor tono "revolucionario" por cuanto,

\footnotetext{
${ }^{34}$ Manuel Pérez Vila, "Estudio preliminar", tomo II (27 abril 1810-5 julio 1811), en Morón, et al. (editores) 1983-1986; II, 1983: xxii-xxiii.
} 
sin el conocimiento de este perdón papal, se dejaba hablar y conocer el deseo del máximo pontífice de que toda su grey, ministros y feligreses, en la extensión de su dominio católico, opusieran por justas causas las resistencias necesarias contra las conductas sangrientas y criminales de las hordas francesas en Europa. Imagen principalmente sostenida en las dos primeras entregas de estas proclamas papales, aderezada con seguridad en la traducción al español por la pluma de Bello, desde el profundo conocimiento de una retórica que presagiaba su Gramática de la lengua castellana "para uso de los americanos". De esta manera, cuando los dolidos feligreses caraqueños pudieron finalmente verificar el perdón papal en la tercera entrega de este Breve Pontificio, las sociedades religiosas se hallaban anímica e ideológicamente preparadas para emprender la expiación de su ira en los rezos y cantos de los Misereres de Cuaresma y las Lamentaciones de Tinieblas.

Con todo, la "lección bien aprendida de 1808" incluía la necesidad de proclamar la feliz instalación de la Junta Suprema, a imitación de la manera en que la Junta de Gobierno lo había hecho en Aranjuez, en 1808, que el mismo Andrés Bello había dado a conocer a la feligresía caraqueña, en la Gazeta de Caracas $\mathrm{N}^{\circ} 7$, del 17 de noviembre de 1808. Sin embargo, ensayar en la Tribuna catedralicia una rimbombante obra musical como la Misa Solemnis de Lamas, los días previos al Jueves Santo, 19 de abril, en la catedral de Caracas, habría sido asociado por la población caraqueña con los preparativos de algún "inesperado" festejo público, que ningún oidor de la ciudad (por muy desprevenido que estuviera) habría pasado desapercibido. La composición de la Misa de difuntos para la ocasión, de José Francisco Velásquez "el joven", con el agregado del citado pasaje monódico a cappella ${ }^{35}$ para la Tribuna, se concretaba sin embargo ideal a los intereses revolucionarios y catedralicios expuestos, ya que incluía partes de una obra conocida y copiada por Pedro Palacios y Sojo, en 1779, para su Oratorio San Felipe Neri de Caracas. Para entonces, José Francisco Velásquez "el joven", de la misma edad de Andrés Bello, era el primer gran "artesano" integrante del "pueblo llano", heredero de los adelantos llevados a cabo en materia musical por su padre José Francisco Velásquez "el viejo", su tío Juan Manuel Olivares, apoyados por las novedades culturales y educativas de su padrino, el nerista Pedro Palacios y Sojo, amigos todos incondicionales del cantante Bartolomé Bello.

Los axiomas revolucionarios del Breve Pontificio publicado por Andrés Bello y la composición eclesiástica de José Francisco Velásquez "el joven” constituían así los preparativos de índole religiosa más relevantes al llamado de los cambios políticos e ideológicos que solicitaría la Junta Suprema de Caracas, defensora del rey Fernando VII, aquel Jueves Santo. Metáfora eclesiástica de la muerte del Antiguo Régimen en el Triduum Sacrum a la espera de la alegría que traería la renovación política después de la Pascua de Resurrección gracias a la "feliz instalación" catedralicia

${ }^{35}$ La tradición del "canto llano" por los capellanes de coro "a cappella" debe comprender aquí, siguiendo la tradición española, al canto gregoriano acompañado por bajón u órgano solo. "Monodia acompañada" sería quizá la terminología más apropiada, si no fuese porque alude a otros devenires históricos de la música occidental. 
del Nuevo Gobierno, proclamado a viva voz con la Missa Solemnis de José Ángel Lamas, el siguiente domingo, 29 de abril.

Por primera vez en la historia de la catedral de Caracas, nadie consideró oportuno multar a los cantantes de la Tribuna por no bajar a sustituir a los capellanes de coro en sus cantos durante la interpretación de la Misa de difuntos de Velásquez. Así se reivindicaron públicamente las injustas causas que promovieron la renuncia del cantante Bartolomé Bello, en abril de 1787. Por el contrario, la magistral sustitución de los ministros de coro por los cantantes de la Tribuna, que ayudó al canónigo José Cortés de Madariaga y al presbítero Francisco José Ribas hallarse en el tiempo y lugar adecuados, fue sin duda el primer gesto de libertad religiosa y artística aceptado por los mantuanos, como presagio de esas otras libertades sobre la desigualdad política, cultural y social que traerían a Venezuela los acontecimientos políticos y eclesiásticos del 19 de abril de 1810. Fue en ese instante sonoro, olvidado en dos siglos, cuando el pardo José Francisco Velásquez "el joven" y el criollo Andrés Bello reivindicaron al mismo tiempo, con este tácito intercambio de favores, y desde la Tribuna de la Iglesia Metropolitana de Caracas, el honor de sus padres músicos.

\section{BIBLIOGRAFÍA}

1. Archivos

Archivo Arquidiocesano de Caracas (AAC).

- $\quad$ Reglas de coro de la esta Santa Yglesia / Formadas en el año pasado de 1728 / Por el Ylt. S. ${ }^{r} D .^{n}$ Juan de Escalona / De feliz recordación. / Publicadas el año de 1747 / Con algunos acordados hechos / por la R. ${ }^{l}$ Audiencia de S. ${ }^{\text {to }}$ / Domingo por coms. ${ }^{n}$ del R[ey] N[uestro] S[eñor], libros diversos 111-L.

- $\quad$ Año 1773 / Ynformación de limpieza de sangre, buena vida y costumbre dada por D. ${ }^{n}$ Bartholomé Bello para vestir avitos clericales, AAC, Petición de hábitos 4-Ec.

- $\quad$ Libro tercero de cuentas de la Archicofradía del Rosario, libros diversos 201-L.

Archivo Audiovisual de la Biblioteca Nacional de Venezuela, Foro Libertador $(\mathrm{AABNV})$.

- $\quad$ Registro “José Ángel Lamas” (RJAL), partitura 21-A.

Archivo de la Catedral de Caracas (ACG).

- $\quad$ Actas del Cabildo Eclesiástico (ACE), libros XVIII, XVIII (duplicado), XIX, XXIV.

Archivo General de Indias (AGI).

- Año 1770 / Cámara / Relación de Personas para Consultar el Obispado de la Iglesia Catedral de Santiago de León de Caracas, Audiencia de Caracas 218 (16 folios).

- $\quad$ Informe (Madrid, 11 de agosto de 1772), Audiencia de Caracas 230 (6 folios).

- $\quad$ Carta (Caracas, 4 de diciembre de 1772), Audiencia de Caracas 320 (1 folio).

- $\quad$ Testimonio / Numero 4 / Contiene la justificación evacuada acerca de los ministros subalternos que se han apartado del servicio del Coro y Capilla de Musica de la Cathedral de Caracas, y plazas que están vacantes; y de los motivos porque aquellos se retiran, y estas no se han provehido, Audiencia de Caracas 964 (23 folios). 
- $\quad$ En vista de la instancia de don Bartolomé Bello, fiscal de la Real Hacienda y Renta de tabaco de la Provincia de Cumaná, que sirve también la plaza de Asesor y Auditor de Guerra de aquel gobierno, Audiencia de Caracas 816 (29 folios).

Archivo General de la Nación (AGN).

- $\quad$ Sección Iglesia, tomo LVII.

Archivo Histórico de la Academia Nacional de la Historia (AHANH).

- Juicio contra José Francisco Velásquez, año 1791, Civiles 9-3710-1 (32 folios).

\section{Fuentes impresas}

\section{Calcaño, José Antonio}

1958/1980 La ciudad y su música. Caracas: Fundarte.

1985 La ciudad y su música. Caracas: Monte Ávila Editores.

Calzavara, Alberto

1987 Historia de la música en Venezuela: periodo hispánico con referencias al teatro y la danza. Caracas: ExLibris/Fundación Pampero.

\section{Coifman, David}

2006 Dialéctica musical de los poderes eclesiásticos durante el obispado de don Mariano Martí (1770-1792). Tesis doctoral, Universidad Complutense de Madrid.

2007 "José Antonio Caro 'de Boesi”" (1758-1814?): primer compositor de la Ilustración musical en Venezuela”, La música y el Atlántico. Relaciones musicales entre España y Latinoamérica. María Gembero Ustárroz y Emilio Ros-Fábregas, editores. Granada: Universidad de Granada, pp. 415-33.

2009 "Música de milicias y cofradías en la Capitanía General de Venezuela (17871798)”. Separata de Monumenta: La música colonial venezolana. Volumen 3. Caracas: Fundación Camerata de Caracas, pp. 3-12.

2010 De obispos, reyes, santos y señas en la historia de la capilla musical de Venezuela (15321804). Madrid: Sociedad Española de Musicología.

2011a “'Monarquía’ y 'Revolución' en la emancipación musical de Venezuela (18041821)", Boletín de la Academia Nacional de la Historia, XCIV/374 (abril-junio, 2011), pp. 37-64.

2011b "Música para la orquesta clásica de la Iglesia Metropolitana de Caracas". Separata de la Monumenta: La música colonial venezolana. Volumen 4. Caracas: Fundación Camerata de Caracas, pp. 3-13.

2011c "The 'Spirit of Independence' in the Fiesta de la Naval of Caracas", Music and Urban Society in Colonial Latin America. Geoffrey Baker y Tess Knighton, editores. Cambridge: University Press, pp. 102-16 y apéndices 3 y 4, pp. 254-74.

2011d "Discurso (et ritornello) sobre la música en la Colonia y la Independencia en Venezuela”. Discurso de orden de la cátedra Gil Fortoul de la Academia Nacional de la Historia de Venezuela, publicado en Boletín de la Academia Nacional de la Historia, XCIV/376 (octubre-diciembre, 2011), pp. 119-141. 
2012 "Música de la emancipación en Venezuela (1810-1821". Separata de la Monumenta: La música colonial venezolana. Volumen 5. Caracas: Fundación Camerata de Caracas.

Duarte, Carlos F.

2001 La vida cotidiana en Venezuela durante el período hispánico. 2 volúmenes. Caracas: Fundación Cisneros.

Guido, WALter

1982 José Ángel Lamas y su época. Caracas: Fundación Biblioteca Ayacucho.

Guido, Walter y José Peñín (editores)

1998 Enciclopedia de la música en Venezuela. 2 volúmenes. Caracas: Fundación Bigott.

Leal Curiel, Carole

2009 "La revolución del orden: el 19 de abril de 1810", Revista Politeia, XXXII/43. Caracas: Instituto de Estudios Políticos, Universidad Central de Venezuela (UCV), pp. 65-86.

LiRA EsPeJo, EduARdo (EDITOR)

1959 José Ángel Lamas: Misa en Re. Partitura de coro y orquesta. [Caracas]: Ediciones musicales de la Radio Nacional.

Miranda Bastidas, Haydée, Asdrúbal Becerra, David Ruiz Chataing (editores).

1999 "Acta del 19 de abril de 1810", Documentos fundamentales de la historia de Venezuela (1770-1993). Caracas: Editorial CEC, p.20.

Molina Martínez, Miguel

2002 Los cabildos y la independencia de Iberoamérica. Granada: Centro de Estudios Municipales y de Cooperación Internacional (CEMCI).

Morón, Guillermo, ET Al. (EDitores)

1983-86 Gazeta de Caracas, Caracas, 1808-1822. 10 tomos. Edición facsimilar de la Academia Nacional de la Historia. Bicentenario del Nacimiento del Libertador Simón Bolívar. Caracas: Biblioteca de la Academia Nacional de Historia.

Piqueras, José Antonio

2010 Bicentenario de libertad. La fragua de la política en España y las Américas. Barcelona: Ediciones Península.

Pino ItUrRieta, Elías

1991 La mentalidad venezolana de la emancipación (1810-1812). Caracas: El Dorado.

Plaza, Juan Bautista

1990 Temas de música colonial venezolana: biografía, análisis y documentación. Caracas: Fundación Vicente Emilio Sojo.

QUinTERo, INÉS

2008 La conjura de los mantuanos. Colección Bicentenario de la Independencia. Caracas: Academia Nacional de la Historia - Universidad Católica Andrés Bello.

Virtuoso, Francisco José

2001 La crisis de la catolicidad en los inicios republicanos de Venezuela (1810-1813). Caracas: Ediciones de la Universidad Católica Andrés Bello. 


\section{Discografía recomendada}

Monumenta: La música colonial venezolana. Volumen. 1. Caracas: Fundación Camerata de Caracas / Banco Mercantil, octubre, 2007. Intérpretes: Camerata Barroca de Caracas, Collegium Musicum "Fernando Silva-Morván”, Isabel Palacios, directora. Gloria anónimo ¿Ambrosio Carreño (1721-1801)?; Magnificat (1778) de Pedro Osío (1726-1806); Misa de difuntos (1779), Misa a dúo (ca. 1780), Tantum ergo (1781), Christus factus est y Dextera Domini (1783), de José Antonio Caro “de Boesi” (1758-¿1814?). Transcripción, edición y selección de las obras por David Coifman.

Monumenta: La música colonial venezolana. Volumen 2. Caracas: Fundación Camerata de Caracas / Banco Mercantil, octubre, 2008. Intérpretes: Camerata Barroca de Caracas, Collegium Musicum "Fernando Silva-Morván”, Isabel Palacios, directora. Stabat Mater (1791), Lamentatio Prima in Sabbato Sancto (1791), Prime Visperce (ca. 1791) y Salve Regina (ca. 1793), de Juan Manuel Olivares (1760-1797). Transcripción, edición, selección, recreación litúrgica y estudio de las obras por David Coifman.

Monumenta: La música colonial venezolana. Volumen 3. Caracas: Fundación Camerata de Caracas / Banco Mercantil, octubre, 2009. Intérpretes: Camerata Barroca de Caracas, Collegium Musicum "Fernando Silva-Morván”, Isabel Palacios, directora. Misa a dúo (1787), Stabat Mater (1798), Tonos de Semana Santa (s. f.): 1. "Alma, acompaña a tu Dios", 2. "Da Pilatos por sentencia" y 3 "La túnica que mi madre me tejió", Trisagio (s. f.), Alleluia. Solemnitas a la Virgen del Rosario (ca. 1800) y Villancicos de Navidad: 1. "Venid, dichosos pastores" (s. f.), 2. "Niño, niño mío" (s. f.) y 3. "Los cielos destilaban alegría" (s. f.), de José Francisco Velásquez "el viejo" (1755-1805); Toques marciales (1761/1769): "La Misa", "La Asamblea", "La marcha de fusileros", "La Generala" y "La Fagina", de Manuel Espinosa de los Monteros (ca.1730-1810). Transcripción, edición, selección y estudio de las obras por David Coifman.

Monumenta: La música colonial venezolana. Volumen 4. (2 cds). Caracas: Fundación Camerata de Caracas / Banco Mercantil, enero, 2011. Intérpretes: Camerata Barroca de Caracas, Sinfónica de la Juventud Venezolana "Simón Bolívar", Isabel Palacios, directora. Salve Regina (ca. 1800), Popule meus (1796/1801), In Monte Oliveti (s. f., ca. 1802-03), Sepulto Domino (1805), Santa Maria “Jaculatoria” (1805), 3. Salve Regina (1806), Invitatorio Sancta Maria y Gradual Benedicta et venerabilis (ca. 1807), Salve Regina (4 movimientos, ca. 1808) y Missa Solemnis (1810) de José Ángel Lamas (1775-1814). Transcripción, edición, selección y estudio de las obras por David Coifman.

Monumenta: La música Colonial venezolana. Volumen 5. Caracas: Fundación Camerata de Caracas / Banco Mercantil, 2012. Intérpretes: Camerata Barroca de Caracas, Orquesta Municipal de Caracas, Isabel Palacios, directora. Oficio de difuntos (1810), Villancico "Vamos, hijas de Sion” (1810), Tono “¡Ay amor!” (ca. 1812 / con copia "octubre, 1816"), Tono "Lucero rutilante de la aurora" (sin fecha), Tono "Cruz, árbol el más noble" (1816) y Tono "Es María norte y guía" (s.f.), de José Francisco Velásquez "el joven" (1781-1822). Transcripción, edición, selección y estudio de las obras por David Coifman. 